\title{
Quantification of the uterine involution and dimensions, hormonal response and reproductive performance of pyometric and healthy dairy cows treated with Dinoprost
}

\author{
R. Masoumi ${ }^{1}$, A. Badiei ${ }^{\# 2}$, F. Mousakhani ${ }^{3}$, E. Dirandeh ${ }^{4}$, M. Zhandi $^{5}$ \& \\ M. Stear ${ }^{6}$ \\ ${ }^{1}$ Department of Animal Science, Faculty of Agriculture, University of Zanjan, Zanjan, Iran. \\ ${ }^{2}$ Department of Clinical Sciences, Veterinary Faculty, Islamic Azad University, Karaj, Alborz, Iran. \\ ${ }^{3}$ Department of Pathobiology, Faculty of Veterinary Medicine, Karaj Branch, Islamic Azad University, Karaj, Iran. \\ ${ }^{4}$ Department of Animal Science, Sari Agricultural Sciences and Natural Resources University, Sari, Iran. \\ ${ }^{5}$ Department of Animal Science, Faculty of Agricultural Science and Engineering, College of Agriculture and Natural \\ Resources, University of Tehran, Karaj, Iran. \\ ${ }^{6}$ Department of Animal, Plant and Soil Sciences, AgriBio, Center for AgriBiosciences, La Trobe University, Melbourne, \\ Australia.
}

(Received 1 March 2017; Accepted 15 October 2017; First published online 14 December 2017)

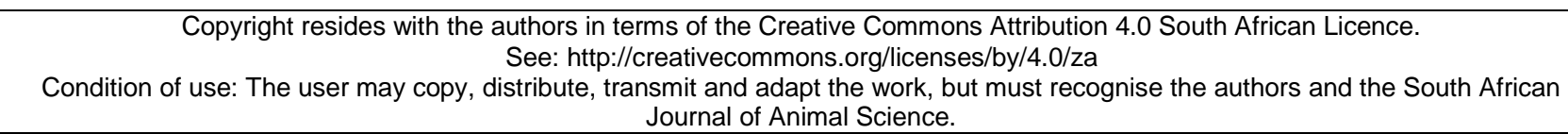

\begin{abstract}
The aim of the present study was to investigate the effects of a PGF $_{2 a}$ analogue (Dinoprost) on involution of the puerperal uterus, especially with pyometra during 35 to 45 days postpartum in multiparous high yielding Holstein dairy cows. At days $40 \pm 5$ postpartum, 1250 cows were ultrasonographically examined. Fifty cows were diagnosed as pyometric. Fifty pyometric and 50 clinically healthy cows were assigned randomly to one of four groups. Groups were: 1.) Pyometric+Dinoprost cows (PD, $n=25$ treated with $25 \mathrm{mg}$ of Dinoprost), 2.) Pyometric+Saline cows (PS, $n=25$ treated with saline), 3.) Healthy+Dinoprost cows (HD, $n=25$ treated with $25 \mathrm{mg}$ of Dinoprost), and 4.) Healthy+Saline cows (HS, $n=25$ treated with saline). All treatments were given intramuscularly. Ultrasonography was performed at the time of examination and 7 days later to evaluate changes in uterine diameter. Treatment with Dinoprost significantly reduced gross uterine diameter in PD in comparison to the PS group in the presence or absence (P4 concentrations $<1 \mathrm{ng} / \mathrm{ml}$ ) of an active corpus luteum. Dinoprost treatment did not decrease gross uterine diameter in groups HD and HS. Luminal diameter was significantly smaller in the PD than in the PS group. Pregnancy rate of PD was greater than PS cows ( $36 \%$ vs $20 \%$, respectively). Days to first service (110 d vs. $140 \mathrm{~d})$ and open days (160 d vs. $190 \mathrm{~d}$ ) were shorter in PD cows than PS cows. It was concluded that injection of $25 \mathrm{mg}$ of Dinoprost to pyometric cows had uterotonic effects in presence or absence of functional corpus luteum. Therefore, this treatment can help uterine involution in puerperal dairy cows affected by pyometra and consequently improved reproductive performance.
\end{abstract}

\footnotetext{
Keywords: Cattle, Dinoprost, pregnancy rate, pyometra, uterine health

\# Corresponding author: abadiei2000@yahoo.com
}

\section{Introduction}

The general goals for post-partum reproductive health in dairy cattle is for the uterus to be completely involuted and free of infection, and for cows to be cyclic by the time they enter the breeding period after 50 to 60 days in milk (DIM) (LeBlanc et al., 2002). After parturition, bacteria from the animal's environment contaminate the uterine lumen of most cattle. Infection persists in the uterus of many animals for more than three weeks, with about $15 \%$ of dairy cattle having signs of clinical endometritis (Sheldon, 2007). Endometritis is an inflammation of the endometrial lining of the uterus without systemic signs, occurring at least 21 days after calving (Barlund et al., 2008), which is often associated with chronic post-partum infection of the uterus with pathogenic bacteria, primarily Arcanobacterium pyogenes, Fusobacterium necrophorum, Trueperella pyogenes, Escherichia coli and Bacteroides Spp (Bondurant, 1999; Karstrup et 
al., 2017). Untreated endometritis progresses to pyometra which is characterized by accumulation of purulent or mucopurulent material within the uterine lumen and distension of the uterus in the presence of a persistent corpus luteum and a closed cervix 43 days or more after calving (Sheldon et al., 2006). Pyometra can be considered a subset of endometritis in which cows ovulate in the presence of a contaminated uterus (Galvão et al., 2011). When cows with chronic endometritis ovulate, pyometra often develops within a few days. During the progesterone-dominated phase the uterus has a reduced resistance to infection (LeBlanc et al., 2002). It has been noted that during endometritis it is the presence of corpus luteum, with its secretion of progesterone, which results in pyometra (Kennedy \& Miller, 1993). Retention of the corpus luteum is believed to be due to a failure in the pulsatile release of uterine PGF Pa $_{2 a}$ (Prostaglandin F2 alpha) which is controlled by an interaction of luteal oxytocin and ovarian steroids (Vighio et al., 1991). Formation of the first corpus luteum after parturition and secretion of progesterone often precede the onset of uterine disease (Lewis, 2004; Abere \& Belete, 2016). However, many spontaneous uterine infections are established within 3 weeks after parturition, before ovulation of the first dominant follicle (Sheldon et al., 2002).

The incidence rate of pyometra varies between herds, but on individual farms as many as $8 \%$ of calvings may be followed by pyometra (Etherington et al., 1985). Lech et al. (1998) reported that pyometra incidence rates may range from 20 to 60 cases per 1,000 cows in all post-partum dairy cows. Inadequately standardized cost data makes it difficult to determine true estimates, but based on studies done in Ohio and Georgia by Bellows et al. (2002), it is estimated that metritis and pyometra cost approximately $\$ 4.70$ per dairy cow. The adverse effects of puerperal metritis, clinical endometritis, subclinical endometritis, and pyometra on reproductive performance have been described sufficiently (Kim \& Kang, 2003; Gilbert et al., 2005; Sheldon \& Dobson, 2004). The duration of pyometra is inversely related to subsequent fertility in dairy cattle. Cattle with pyometra lasting longer than two months and those with large amounts of intrauterine pus have lesser chances of subsequent fertility (Roberts, 1971). Complete recovery and conception is more likely in cases that have existed for less than 120 days. Cases of longer duration are reported to produce degenerative uterine changes (Roberts, 1971);hence, increasing the culling rate. Today the treatment of choice is administration of $\mathrm{PGF}_{2 \alpha}$ or its analogs at normal luteolytic doses. Exogenous $\mathrm{PGF}_{2 \alpha}$ induces luteolysis, reduces progesterone, and enables the uterus to resolve infections. Expulsion of exudate and bacterial clearance of the uterus follows in $90-100 \%$ of treated cases.

The aim of this study was to evaluate the efficacy of Dinoprost injection on involution of the puerperal uterus, especially with pyometra during 35 to 45 days postpartum in multiparous high yielding dairy cows.

To the best knowledge of the authors, there are not sufficient studies investigating the effects of $\mathrm{PGF}_{2 \alpha}$ on uterine diameter changes in pyometric cows. It is also not clear to what extent does treatment with PGF $_{2 \alpha}$ affect uterine dimensions. We hypothesized that the treatment with Dinoprost in pyometric cows would decrease uterine dimension sizes which are probably independent of luteolysis and are probably due to uterotonic effects of Dinoprost. This reduction may result in improved uterine involution and reproductive performance of pyometric dairy cows. Therefore, our null hypothesis was that treatment with Dinoprost has similar effects on uterine dimensions, hormonal status and reproductive performance of healthy and pyometric cows.

\section{Materials and Methods}

A total of 1,250 multiparous cows (parity range 1 to 6 calvings) from eight commercial Holstein dairy farms located in Provinces of Tehran and Karaj, Iran were examined 35 to 45 days postpartum. The herds ranged from 150 - 800 milking cows and the rolling herd averages were between $9000-12,000 \mathrm{~kg}$ of milk/cow per year. Lactating dairy cows were housed in corrals and milked three times daily. Transition dairy cows (between $21 \mathrm{~d}$ before expected parturition and $21 \mathrm{~d}$ post-partum) were housed in pre- and post-partum dry lot pens. Within a herd, cows were fed the same total mixed ration (TMR) formulated to meet or exceed the NRC (National Research Council, 2001) nutrient requirements for lactating Holstein cows weighing 680 $\mathrm{kg}$ and producing $45 \mathrm{~kg}$ of $3.5 \%$ FCM (Fat Corrected Milk). Reproductive management varied among farms, however, all dairy farms relied on estrus detection for most of their breeding and their voluntary waiting periods were set to $40-60 \mathrm{DIM}$. The gynaecological examinations were performed weekly beginning on the day $10 \pm 3$ post-partum. The clinical examination included ultrasonographical and transrectal palpation of the uterus, cervix, and ovaries.

Ultrasonography was conducted using a 7.5-MHz transrectal linear transducer (Agro Scan, France). Uterine characteristics of the pyometric and clinically healthy cows were assessed according to validated methodology (Sheldon et al., 2003; Barlund et al., 2008). All transrectal palpations, uterine measurements, and ultrasonographic exams were performed by the same veterinarian throughout the experiment. Pyometra 
was defined as accumulation of mixed echo density fluid in the uterine lumen and distension of the uterus with thin walls and without uterine tone in the presence of a corpus luteum. The diameters of the uterine horns were measured using the internal calipers of the ultrasound machine. The larger diameter of the uterine horns was initially identified and two diameters of the enlarged uterine horn were evaluated approximately $10 \mathrm{~cm}$ from the bifurcation of the uterus. If intraluminal fluid was detected during the initial ultrasound examination of the uterus an attempt was made to measure the luminal diameter in the area of the greatest fluid accumulation (Barlund et al., 2008). Minimal pressure was applied with the ultrasound transducer to the top of the uterus to avoid deformation of the uterine horns when performing these measurements. The first measurement was from serosa to serosa to obtain the gross diameter of the uterine horn (Sheldon \& Dobson, 2000). The second measurement was from submucosa to submucosa to obtain lumen diameter. The difference between the first and the second measurements estimated uterine wall thickness. The third measurement was from submucosa to vascular layer of uterus to obtain the endometrium diameter. Measuring the endometrium diameter of pyometric cows was technically difficult because of the accumulated pus and fluids which increased the inner pressure of uterus making measurements inaccurate. Thus, instead of endometrium diameter, the luminal diameter of pyometric cows were measured and reported. Therefore, variables considered in the current trial were: 1.) uterine diameter changes which were obtained from serosa to serosa measurements. 2.) endometrial diameter changes for healthy cows which were obtained from submucosa to vascular layer measurements, 3.) luminal diameter changes specifically for pyometric cows which were obtained from submucosa to submucosa, and 4.) plasma progesterone, estradiol and haptoglobin concentration changes which were measured with commercial kits.

Fifty cows out of 1,250 were diagnosed as pyometric cows 35 - 45 days post-partum and served as treatment groups as follows: Cows in group PD ( $n=25$; Pyometric+Dinoprost) were treated intramuscularly with $25 \mathrm{mg}$ of Dinoprost. Cows in group PS ( $\mathrm{n}=25$; Pyometric+Saline) were treated with $5 \mathrm{ml}$ saline, also by intramuscular injection. Fifty healthy cows with clinically normal uteri also served as control groups as follows: Cows in group HD ( $n=25$; Healthy+Dinoprost) were treated with $25 \mathrm{mg}$ of Dinoprost. Cows in group HS ( $n=25$; Healthy+Saline) were treated with $5 \mathrm{ml}$ saline. $\mathrm{PGF}_{2 \alpha}$ (Dinoprost tromethamine; $25 \mathrm{mg} /$ dose; Enzaprost) was from Ceva Santé Animale, France.

Concurrent with ultrasonography, blood samples of progesterone, estradiol and haptoglobin determination were collected at the time of treatments and 7 days later from the tail vein or artery into heparinized tubes. The collected blood was immediately centrifuged at $3000 \times \mathrm{g}$ for $20 \mathrm{~min}$ and plasma was stored at $-20^{\circ} \mathrm{C}$ until assayed. Plasma progesterone concentration was used as a criterion to classify cows to groups having a functional corpus luteum or lacking a functional corpus luteum at the time of Dinoprost or saline injection. Cows with plasma P4 $>1.0 \mathrm{ng} / \mathrm{mL}$ were classified as having a functional corpus luteum present, whereas cows with plasma P4 $<1.0 \mathrm{ng} / \mathrm{mL}$ were classified as lacking a functional corpus luteum as described previously (Rivera et al., 2005; Masoumi et al., 2012) The progesterone and estradiol levels were determined by commercial Elisa kits (DRG Ins. GmbH, Germany) as described previously by Dirandeh et al. (2015a). The intra- and interassay coefficients of variation were 3.7 and $8.3 \%$ for P4 and 2.71 and 6.72 for Estradiol. The haptoglobin levels were also determined by commercial Elisa Kit (Bio-X Diagnostics, Belgium). Ultrasonographic findings, plasma progesterone, estradiol and haptoglobin concentrations were analyzed by ANOVA mixed models using SAS software (SAS 9.3; 2003; SAS Institute Inc., Cary, NC, USA) for Windows with the following model:

$$
Y i j k=\mu+\alpha_{i}+\mathrm{T}_{j}+(\alpha \mathrm{T})_{i j}+\mathrm{e}_{\mathrm{ijk}}
$$

Where: $\mu$ is the population mean, $\alpha_{i}$ is the treatment effect, $\mathrm{T}_{j}$ is the effect of sampling day or time, $\alpha \mathrm{T}_{i j}$ is the interaction between time and treatment, and $\mathrm{e}_{\mathrm{ijk}}$ is residual effects.

The data were analyzed separately for pyometric cows having no functional corpus luteum (P4 concentrations < $1 \mathrm{ng} / \mathrm{ml}$, Dirandeh et al., 2015b; Masoumi et al., 2017) to determine if uterine diameter changes were solely due to luteolysis or other effects of PGF $_{2 a}$ such as uterotonic effects. Rankit plots and Wilk-Shapiro tests were used to assess the normality of the residuals. Significance was declared at $P<0.05$. The binomially distributed reproductive data were analyzed using Logistic procedure of SAS. Significance was declared at $P<0.05$ unless otherwise indicated. 


\section{Results}

The results showed that treatment of pyometric multiparous cows with $25 \mathrm{mg}$ Dinoprost (PD cows) at 35 - 45 days post partum, significantly $(P<0.05)$ reduced the uterine diameter in comparison to saline treated pyometric cows (PS cows) 7 days after Dinoprost injection (Figure 1). The mean uterine diameter (serosa to serosa) of PD and PS groups at the time of Dinoprost injection and 7 days later were $(61 \pm 2.28 ; 35 \pm 2.20$ $\mathrm{mm})$ and $(49 \pm 2.35 ; 52 \pm 2.26 \mathrm{~mm})$, respectively. The effect of Dinoprost injection on uterine diameter in clinically healthy cows (HD cows) was not significant in comparison to saline treated clinically healthy cows (HS cows) $(P>0.05)$ (Figure 1). The mean uterine diameter of pyometric cows and healthy cows at the beginning of treatments were $55 \pm 1.77$ and $38 \pm 1.96 \mathrm{~mm}$, respectively. The difference between mean uterine diameter of pyometric and healthy cows at the beginning of treatments was significant $(P<0.05)$.
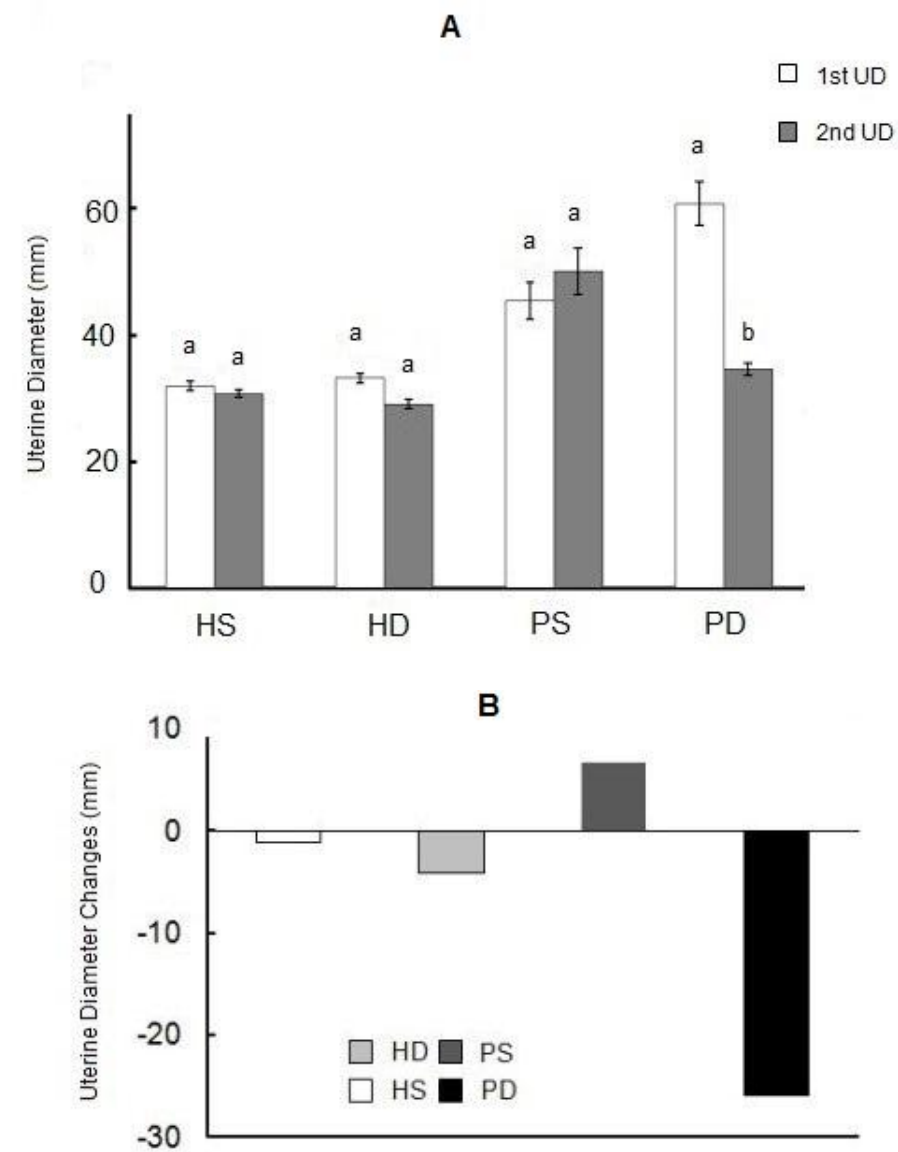

Open bars $=$ First uterine diameter at the time of treatments. Filled bars $=$ second uterine diameter 7 days after treatments. $\mathrm{X}$ axis represents experimental groups.

Figure 1 Least Square Mean $( \pm S E)$ uterine diameter measurements $(A)$ and uterine diameter changes $(B)$ in healthy cows treated with saline (HS), healthy cows treated with Dinoprost (HD), pyometric cows treated with saline (PS) and pyometric cows treated with Dinoprost (PD).

Analysis of data for cows lacking a functional corpus luteum (Progesterone $<1 \mathrm{ng} / \mathrm{ml}$ ) showed that Dinoprost injection significantly decreased the uterine diameter and luminal diameter $(P<0.05)($ Figure 2$)$. The mean uterine diameter at the time of treatment and 7 days later in pyometric cows lacking a functional corpus luteum treated with Dinoprost was $(50.5 \pm 6.14,31.5 \pm 3.06 \mathrm{~mm})$, in pyometric cows lacking a functional corpus luteum treated with saline was $(43.00 \pm 3.13,55.00 \pm 9.67 \mathrm{~mm})$, in clinically healthy cows lacking a functional corpus luteum treated with Dinoprost was (33.66 $\pm 1.60,32.00 \pm 1.73 \mathrm{~mm})$ and in clinically healthy cows without a functional $\mathrm{CL}$ treated with saline was $(30.72 \pm 1.16,30.30 \pm 1.08 \mathrm{~mm})$ respectively. The results showed that treatment of healthy cows lacking a functional corpus luteum with 
Dinoprost did not decrease uterine diameter in comparison to healthy cows lacking a functional corpus luteum treated with saline $(P<0.05)$ (Figure 2).

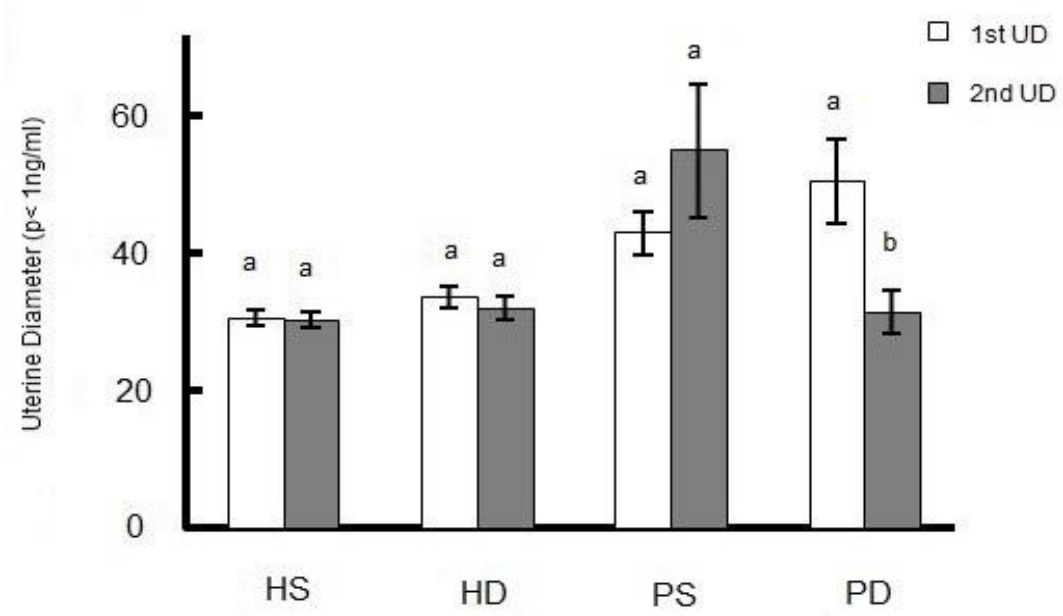

Open bars $=$ First uterine diameter at the time of treatments. Filled bars $=$ second uterine diameter 7 days after treatments. $\mathrm{X}$ axis represents experimental groups.

Figure 2 Least Square Mean ( \pm SE) uterine diameter measurements in healthy cows treated with saline (HS), healthy cows treated with Dinoprost (HD), pyometric cows treated with saline (PS) and pyometric cows treated with Dinoprost (PD) with plasma progesterone concentrations less than $1 \mathrm{ng} / \mathrm{ml}$.

Dinoprost significantly reduced the mean luminal diameter in PD cows in comparison to PS cows ( $P$ $<0.05)$ (Figure 3). The mean luminal diameter in PD and PS cows were $(46 \pm 3.05 ; 8 \pm 2.50 \mathrm{~mm})$ and $(33 \pm$ $3.15 ; 40 \pm 2.58 \mathrm{~mm}$, Figure 3) respectively. Treatment of HD cows had no significant effect on mean endometrial diameter $(P>0.05)$ (Figure 4). The mean endometrial diameter in HD and HS cows were $(16 \pm$ $3.32,8 \pm 2.72 \mathrm{~mm})$ and $(16 \pm 3.23 ; 10 \pm 2.65 \mathrm{~mm}$ ) (Figure 4).

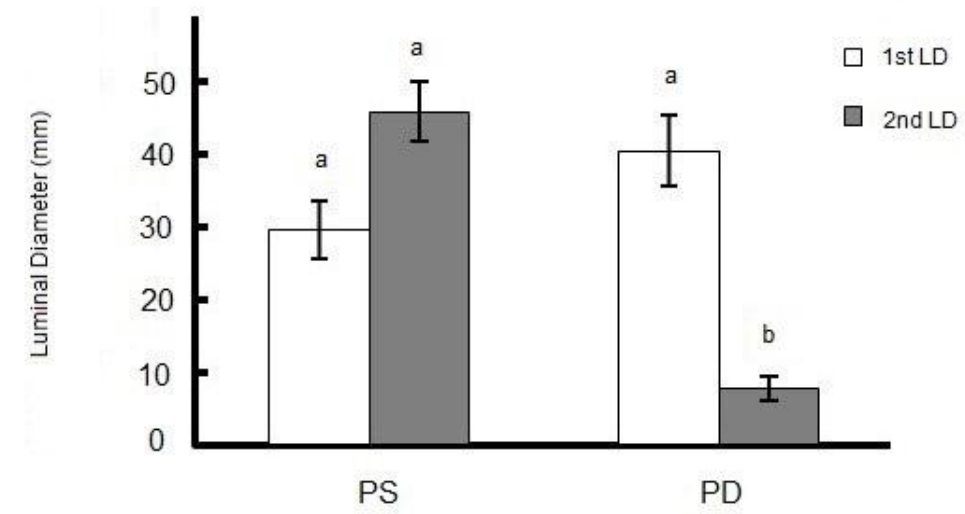

Open bars $=$ First Luminal diameter at the time of treatments. Filled bars $=$ second Luminal diameter 7 days after treatments. $\mathrm{X}$ axis represents experimental groups.

Figure 3 Least Square Mean ( $\pm S E)$ luminal diameter measurements in pyometric cows treated with saline (PS) and pyometric cows treated with Dinoprost (PD). 


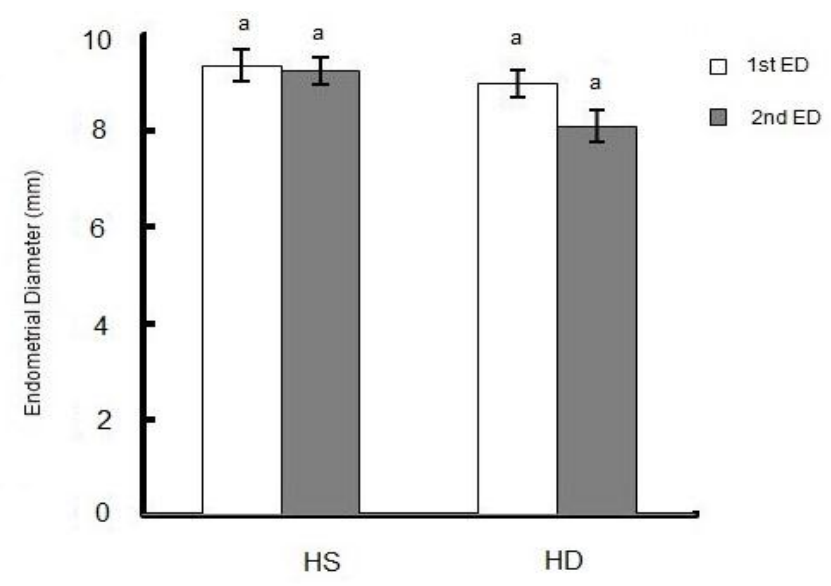

Open bars $=$ First endometrium diameter at the time of treatments. Filled bars $=$ second endometrium diameter 7 days after treatments. $\mathrm{X}$ axis represents experimental groups.

Figure 4 Least Square Mean ( \pm SE) endometrium diameter measurements in healthy cows treated with saline (HS) and healthy cows treated with Dinoprost (HD).

The effect of Dinoprost treatment on plasma progesterone (Figure 5), estradiol (Figure 6), and haptoglobin (Figure 7$)$ concentrations was not significant $(P>0.05)$.

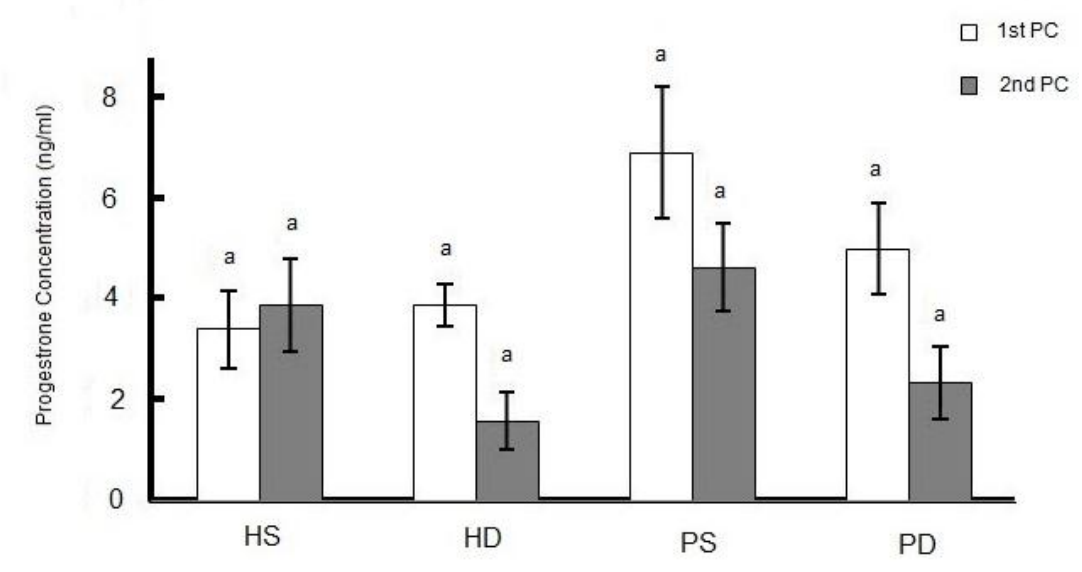

Open bars $=$ First progesterone concentration at the time of treatments. Filled bars $=$ second progesterone concentration 7 days after treatments. $X$ axis represents experimental groups.

Figure 5 Least Square Mean $( \pm S E)$ plasma progesterone concentration $(\mathrm{ng} / \mathrm{ml})$ in healthy cows treated with saline (HS), healthy cows treated with Dinoprost (HD), pyometric cows treated with saline (PS) and pyometric cows treated with Dinoprost (PD).

Pregnancy rate of PD was greater $(P<0.05)$ than PS cows (36\% vs $20 \%$ respectively) but it did not differ $(P>0.05)$ in healthy cows (44\% vs. $48 \%$ in HP and HS groups, respectively). Days to first service of PD cows $(110 \mathrm{~d})$ was shorter $(P<0.05)$ than PS cows $(140 \mathrm{~d})$ and also open days of PD cows $(160 \mathrm{~d})$ was shorter $(P<0.05)$ than PS cows (190) (Table 1$)$. 


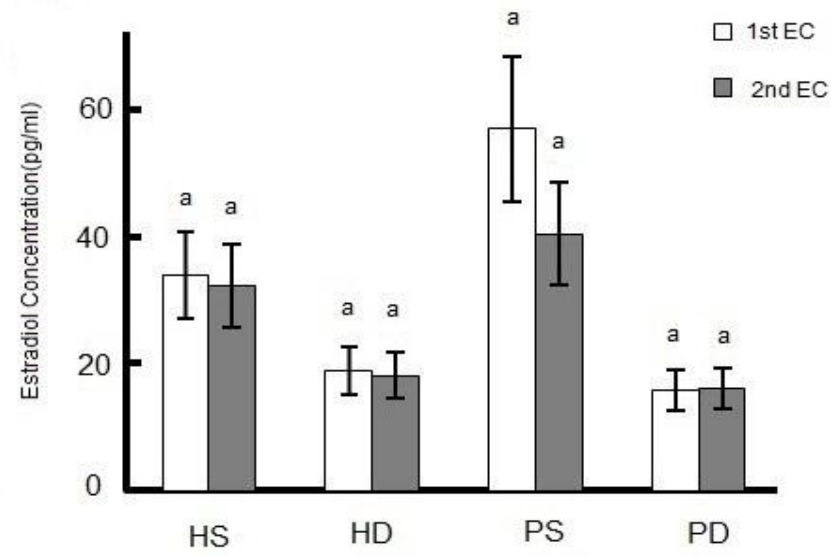

Open bars $=$ First estradiol concentration at the time of treatments. Filled bars $=$ second estradiol concentration 7 days after treatments. $\mathrm{X}$ axis represents experimental groups.

Figure 6 Least Square Mean $( \pm S E)$ plasma estradiol concentration $(\mathrm{pg} / \mathrm{ml})$ in healthy cows treated with saline (HS), healthy cows treated with Dinoprost (HD), pyometric cows treated with saline (PS) and pyometric cows treated with Dinoprost (PD).

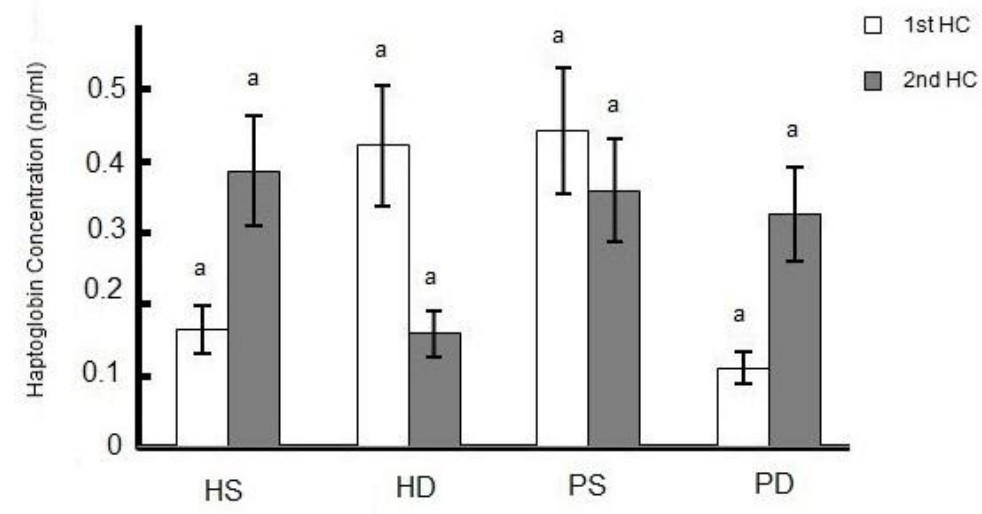

Open bars $=$ First haptoglobin concentration at the time of treatments. Filled bars $=$ second haptoglobin concentration 7 days after treatments. $\mathrm{X}$ axis represents experimental groups.

Figure 7 Least Square Mean ( \pm SE) plasma haptoglobin concentration $(\mathrm{ng} / \mathrm{ml})$ in healthy cows treated with saline (HS), healthy cows treated with Dinoprost (HD), pyometric cows treated with saline (PS) and pyometric cows treated with Dinoprost (PD).

Table 1 Pregnancy rate (after first Al), day to first service and open days in healthy and pyometric cows treated with or without Dinoprost

\begin{tabular}{|c|c|c|c|c|c|c|}
\hline & \multicolumn{4}{|c|}{ Experimental Groups } & \multirow[b]{2}{*}{ SEM } & \multirow[b]{2}{*}{ P Value } \\
\hline & HS & HD & PS & PD & & \\
\hline Open days & $120^{\mathrm{a}}$ & $132^{a}$ & $190^{\mathrm{b}}$ & $160^{\mathrm{C}}$ & 7.53 & 0.04 \\
\hline Days to first service & $75^{a}$ & $70^{a}$ & $140^{b}$ & $110^{c}$ & 9.16 & 0.01 \\
\hline Pregnancy rate & $44^{\mathrm{a}}$ & $48^{a}$ & $20^{b}$ & $36^{c}$ & 1.2 & 0.01 \\
\hline
\end{tabular}




\section{Discussion}

This study was designed to investigate the effects of Dinoprost, a natural occurring $\mathrm{PGF}_{2 a}$ analogue, on uterine diameter changes in pyometric and healthy cows in presence or absence of functional corpus luteum. We hypothesized that Dinoprost would improve the uterine involution process in pyometric cows with its non-luteolytic effects in the absence of a functional corpus luteum. However, Dinoprost has luteolytic effects and would demise a functional corpus luteum and induce estrous to clean the uterus of accumulated pus in cows bearing a functional corpus luteum. When endometritis progresses to pyometra, the uterus accumulates a considerable amount of purulent exudate, which is usually palpable because the cervix is typically constricted enough to prevent the exudate from draining freely causing the uterus to become distended (Arthur et al., 1982). Treatment of pyometra does not seem to be controversial (Gilbert \& Schwark 1992). The use of prostaglandins to treat pyometra has been recommended and evaluated (Steffan et al., 1984; Etherington et al., 1985). However, this study did not attempt to assess the therapeutic effect of the $\mathrm{PGF}_{2 \alpha}$ treatment on pyometra. The transrectal ultrasonography was used to diagnose pyometric cows and measure uterine diameters. Transrectal ultrasonography is a non-invasive and reliable method to investigate the reproductive tract including uterine dynamics (involution) and has been used to detect intrauterine fluid accumulation associated with endometritis (Dhaliwal et al., 2001; Kasimanickam et al., 2004; 2005) and offers the advantage of an immediate diagnosis. Transrectal ultrasonography for uterine cross-sectional images had high coefficients of determination (Okano and Tomizuka, 1987). Fifty out of 1,250 cows (4\%) in 8 commercial dairy farms were detected as pyometric cows. This is in agreement with what was reported by Etherington et al. (1985) and Lech et al. (1988) who indicated an incident rate of 8 and 2 to 6 percent in dairy herds. Sheldon et al. (2008) stated that pyometra comprises less than 5 percent of clinical cases of uterine diseases.

The results of this study demonstrated that $25 \mathrm{mg}$ of Dinoprost reduced the uterine diameters of pyometric multiparous cows treated 35 - 45 days post-partum in the presence or absence of a functional corpus luteum, but did not have a significant effect on uterine diameters in healthy multiparous cows. Reduction in size is thought to be a response of myometrial contractility (Melendez et al., 2004) following the demise of an functional corpus luteum and induction of estrus in cows having a $\mathrm{PGF}_{2 \alpha}$ responsive corpus luteum. The estrus leads to physical expulsion of bacterial contaminants and inflammatory products as well as a possible improvement in the uterine defenses under low progesterone (Kasimanickam et al., 2005). The $\mathrm{PGF}_{2 \alpha}$ administration positively influenced uterine involution and induced estrus in cows with luteal tissue (Lindell \& Kindahl 1983; Young \& Anderson 1986). Nevertheless, the effect of PGF $_{2 \alpha}$ did not depend on presence of a functional corpus luteum at the time of treatment (Galvao et al., 2009). In our study, mean plasma progesterone concentration at the time of treatment and 7 days later was not significantly different between Dinoprost treated and saline treated pyometric cows. Hence, the luteolytic effects of Dinoprost would not justify reductions in uterine diameters. Blood samples for estradiol measurement were taken every week on herd visits. However, it seems that timing of blood sampling for estradiol assays was not performed at the appropriate time after treatment with Dinoprost. Estradiol measurements one week after Dinoprost injection may not have a good value of interpretation because estrus usually occurs in 3 - 4 days following $\mathrm{PGF}_{2 \alpha}$ treatment (Gustafsson et al., 1976; Masoumi et al., 2017). Acute phase proteins are typical pathological responses to tissue damage or inflammation produced by infections, trauma, neoplasia, or other causes. Haptoglobin is one of the acute-phase proteins which has been considered as the most reactive proteins in cattle (Melendez et al., 2004). Any inflammatory process such as infection, extreme stress, systemic infections and immune responses may increase the levels of plasma haptoglobin in cattle (Cheong et al., 2017). The mean concentration of haptoglobin in our study was not significantly different between Dinoprost treated pyometric cows and saline treated pyometric cows at the time of treatments and 7 days later. Melendez et al. (2004) injected two doses of $\mathrm{PGF}_{2 a} 8 \mathrm{~h}$ apart on day 8 post-partum to cows having acute puerperal metritis. $\mathrm{PGF}_{2 a}$ could not alter plasma haptoglobin concentration in that study. However, haptoglobin concentration reduced over 4 days after treatments in $\mathrm{PGF}_{2 \alpha}$ treated and not treated groups. Perhaps this resulted from greater variability of haptoglobin among animals (Hirvonen et al., 1999). Melendez et al. (2004) stated that if $\mathrm{PGF}_{2 \alpha}$ reduced the diameter of uterine horns in cows that developed metritis, it is reasonable to suggest that the size of the uterus decreased, but does not necessarily indicate that the inflammation and infection was resolved. The mean concentration of haptoglobin between pyometric and healthy cows at the beginning of treatments was not significant in our study. It seems that inflammatory response in pyometric cows was not high enough in our study to increase haptoglobin concentrations in affected animals. It has been reported that in pyometric cattle (Huzzey et al., 2009) and mares (El-Bahr \& ElDeeb, 2016) the levels of haptoglobin increases in response to uterine contamination in compare to control groups. Taking all of the above into consideration, we suggest that, Dinoprost reduced the uterine diameter 
and luminal diameter in pyometric cows mostly by its uterotonic effects, since it could not influence plasma progesterone, estradiol, and haptoglobin concentrations.

We analyzed the uterine diameter and luminal diameter changes this time in pyometric cows having no functional corpus luteum (P4 $<1 \mathrm{ng} / \mathrm{ml})$. Although it has been stated that a physiologic basis for the use of $\mathrm{PGF}_{2 \alpha}$ in cows without a luteal structure on the ovary has not been established (Benmrad and Stevenson 1986), few studies have shown beneficial effects of PGF $_{2 a}$ treatment in cows without a palpable corpus luteum and/or elevated progesterone levels (Steffan et al., 1984; Young \& Anderson 1986). The results showed that Dinoprost treatment in pyometric cows with low progesterone concentration reduced uterine diameter and luminal diameter. This positive effect of PGF2 $\alpha$ on uterine involution on cows lacking a functional corpus luteum as found in our study, was already described (Bonnett et al., 1990). Increased uterine contraction and favorable factors involved in uterine defense mechanisms were induced (Mortimer et al., 1984; Bonnett et al., 1990). A single administration of Dinoprost in healthy cows 14 to 28 days post partum improved conception rate, particularly in cows with a serum progesterone value of less than 0.5 $\mathrm{ng} / \mathrm{ml}$ (Young et al., 1984). Young et al. (1984) and Young and Anderson (1986) stated that this benefit of prostaglandin therapy was not the consequence of luteolysis, but the beneficial effect of $\mathrm{PGF}_{2 \alpha}$ administered post partum is rather the result of myometrial contraction and thereby accelerated uterine involution (Gustafsson, 1984; Garcia-Villar et al., 1987). Perhaps PGF $_{2 \alpha}$ has a role in addition to inducing luteolysis in resolving pyometra. In a study with ewes (Wade \& Lewis, 1996), exogenous PGF $_{2 \alpha}$ enhanced utero-ovarian release of natural $P G F_{2 \alpha}$. This shows that an increase in uterine $P G F_{2 \alpha}$ could enhance neutrophil movement to the uterus. A well-documented effect of $\mathrm{PGF}_{2 \alpha}$ is its ability to contract smooth muscles (Masoumi et al., 2011) and to increase uterine tone (Lindell et al., 1982). In our study, Dinoprost could not influence uterine diameter and endometrial diameter 35-45 days post-partum in healthy cows. This is in accordance with the results of Guilbault et al. (1988) and Hirsbrunner et al. (2006) who reported no beneficial effects of PGF $2 a$ treatments on uterine involution of healthy cows. Hirsbrunner et al. (2006) evaluated a single dose of PGF $2 a$ on a uterus administered at 21-35 days post partum giving the no size difference a week or fourteen days later. It does not seem that PGF2 $\alpha$ treatments would improve uterine involution 35-45 days post partum in healthy cows, because uterine involution is usually concluded around day 45 postpartum (Kiracofe, 1980; Badiei et al., 2014). However, others have reported that in the early post partum period, even a single administration of $\mathrm{PGF}_{2 \alpha}$ does accelerate uterine involution and hasten a return to fertile ovarian cyclicity (Gustafsson et al., 1976; Lindell \& Kindahl, 1983; Kindahl et al., 1984; Young, 1989).

There was no significant difference in progesterone concentration between pyometric cows that responded to the treatment by reducing the luminal diameter and the group not responding. This is in accordance with Gustafsson et al. (1976) who reported no significant difference of PGF $_{2 \alpha}$ injection on progesterone concentration between the group of pyometric cows that responded to the treatment and the group not responding. However, by most definitions, pyometra is confined to cows with an active corpus luteum, and $\mathrm{PGF}_{2 \alpha}$ would cause luteolysis, decreasing progesterone to permit the uterus to resolve the infection (Gustafsson, 1984; Gilbert \& Schwark 1992). Mean progesterone concentration was also not significantly different between healthy cows treated with Dinoprost or saline. Mean plasma progesterone concentration at the beginning of treatments was significantly different between healthy cows and pyometric cows. This is in accordance with the most accepted definition of pyometra which is characterized by high levels of progesterone in pyometric cows (Gustafsson, 1984; Gilbert \& Schwark, 1992).

Recently Cheong et al. (2017) determined the effects of uterine and systemic inflammatory responses to uterine bacterial contamination at calving in 53 multiparous dairy cows on the growth and ovulatory outcomes of the first dominant follicle postpartum. Interestingly, elevated systemic inflammation (which was characterized by higher concentrations of Haptoglobin) during the early postpartum period was negatively associated with the ovulatory status of the first dominant follicle and reproductive performance of cows. In addition, contamination of uterus with Trueperella pyogenes at 3 weeks postpartum significantly reduced the risk of pregnancy at 150 days in milk (Gilbert and Santos, 2016). Results of the present study showed that Dinoprost injection increased pregnancy rate in pyometric cows which is consistent with previous studies (Mortimer et al., 1984; El-Tahawy et al., 2011). El-Tahawy et al. (2011) reported that treatment with PGF 2 , $\mathrm{PGF}_{2 \alpha}+$ oxytetracycline and $\mathrm{PGF}_{2 \alpha}+$ cephapirin increased the pregnancy rate by $53 \%, 75 \%$, and $56 \%$, respectively, relative to control cows. Exogenous $\mathrm{PGF}_{2 \alpha}$ induces luteolysis, reduces progesterone, and enables the uterus to resolve infections due to rising estradiol levels. Expulsion of exudate and bacterial clearance of the uterus follow in $90-100 \%$ of treated cases. Results also showed that Dinoporst injection to pyometric cows decreased open days and this was consistent with reports by Mortimer et al. (1984) who indicated that the number of days open for pyometra cows was $98.7 \mathrm{~d}$ and for non-pyometra cows it was $77.0 \mathrm{~d}$. Recommended treatments for bovine pyometra included mechanical removal of the mucopurulent material, uterine antibiotic infusion and hormone therapy (oxytocin, estrogen, PGF $\left._{2 a}\right)($ Roberts, 1971). 


\section{Conclusions}

It was therefore concluded that $25 \mathrm{mg}$ of Dinoprost administered at 35 - 45 days post partum to pyometric dairy cows reduced their uterine and luminal diameter in the presence or absence of a functional corpus luteum. It was also concluded that administration of Dinoprost injection to clinically healthy cows would not have beneficial effects on uterine involution when administered at 35-45 days post partum.

\section{Acknowledgments}

The authors extend their appreciation to Ceva Santé Animale, France for providing Dinoprost used in this study. The authors also would like to recognize the considerable contributions and valuable assistance of the participating herd owners.

\section{Authors' Contributions}

$A B$ designed the research project and performed farm experiments. RM and FM performed statistical analysis. RM wrote the manuscript. FM analyzed blood samples. ED collected and analyzed reproductive data and wrote the reproductive section of the manuscript. Critical revisions of the manuscript were performed by $A B, M S$ and $M Z$.

\section{Conflict of Interest Declaration}

There is no conflict of interest.

\section{References}

Abere, T. \& Belete, H., 2016. Infections of the uterus on postpartum cows. J. Reprod. Infertil. 7 (2), 34-40, 2016.

Arthur, G.H., Noakes, D.E. \& Pearson, H., 1982. Veterinary Reproduction and Obstetrics. Bailliere Tindall, London.

Badiei, A., Aliverdilou, A., Amanlou, H., Beheshti, M., Dirandeh, E., Masoumi, R., Moosakhani, F. \& Petit, H.V., 2014. Postpartum responses of dairy cows supplemented with $n-3$ fatty acids for different durations during the peripartal period. J. Dairy. Sci. 97, 6391-6399.

Barlund, C., Carruthers, T., Waldner, C. \& Palmer C., 2008. A comparison of diagnostic techniques for postpartum endometritis in dairy cattle. Theriogenology 69, 714-723.

Bellows, D., Ott, S. \& Bellows, R., 2002. Cost of reproductive diseases and conditions in cattle. Prof. Anim. Sci. 18, 2632.

Benmrad, M. \& Stevenson, J.S., 1986. Gonadotropin-Releasing Hormone and Prostaglandin F2 [alpha] for postpartum dairy cows. estrous, ovulation, and fertility traits. J. Dairy. Sci. 69, 800-811.

Bondurant, R., 1999. Inflammation in the bovine female reproductive tract. J. Anim. Sci. 77, 101-110.

Bonnett, B.M., Etherington, W.D. \& Martin, S.W., 1990. Effect of prostaglandin administration to Holstein-Friesian cows at day 26 post-partum on clinical findings, and histological and bacteriological results of endometrial biopsies at day 40. Theriogenology 33, 877-890.

Cheong, S.H., Sá Filho, O. G., Absalon-Medina, V. A., Schneider, A., Butler, W. R. \& Gilbert, R. O., 2017. Uterine and systemic inflammation influences ovarian follicular function in postpartum dairy cows. PloS one, 12(5), e0177356.

Dhaliwal, G., Murray, R. \& Woldehiwet, Z., 2001. Some aspects of immunology of the bovine uterus related to treatments for endometritis. Anim. Reprod. Sci. 67, 135-152.

Dirandeh, E., Rezaei, Roodbari, A. \& Colazo, M.G., 2015a. Double-Ovsynch, compared with presynch with or without $\mathrm{GnRH}$, improves fertility in heat-stressed lactating dairy cows. Theriogenology 83,438-443.

Dirandeh, E., Rezaei Roodbari, A., Gholizadeh, M., Deldar, H., Masoumi, R., Kazemifard, M. \& Colazo. M.G., 2015b. Administration of prostaglandin F2 $\alpha 14$ d before initiating a G6G or a G7G timed-Al protocol increased circulating progesterone prior to Al and reduced pregnancy loss in multiparous Holstein cows. J. Dairy. Sci. 98, 5414-5421.

El-Bahr, S.M. \& El-Deeb, W.M., 2016. Acute-phase proteins, oxidative stress biomarkers, proinflammatory cytokines, and cardiac troponin in Arabian mares affected with pyometra. Theriogenology 86, 1132-1136.

El Tahawy, A.S. \& Sharkawy, A., 2014. The Influence of Different Hormonal Therapies on the Reproductive, Productive and Economic Efficiency of Early Postpartum Dairy Cows. J. Dairy. Vet. \& Anim. Res. 1(2), 00011.

Etherington, W., Martin, S., Dohoo, I. \& Bosu, W., 1985. Interrelationships between ambient temperature, age at calving, postpartum reproductive events and reproductive performance in dairy cows. a path analysis. Can. J. Comp. Med. 49, 254-260.

Galvao, K., Frajblat, M., Brittin, S., Butler, W., Guard, C. \& Gilbert, R., 2009. Effect of prostaglandin F2 [alpha] on subclinical endometritis and fertility in dairy cows. J. Dairy. Sci. 92, 4906-4913.

Galvão, K.N., Risco, C. \& Santos, J.E.P., 2011. Identifying and treating uterine disease in dairy cows. University of Florida, IFAS extension.

Garcia-Villar, R., Marnet, P., Laurentie, M. \& Toutain, P., 1987. Fenprostalene in cattle. Evaluation of oxytocic effects in ovariectomized cows and abortion potential in a 100-day pregnant cow. Theriogenology 28, 467-480.

Gilbert, R.O. \& Santos, N.R., 2016. Dynamics of postpartum endometrial cytology and bacteriology and their relationship to fertility in dairy cows. Theriogenology $85,1367-1374$

Gilbert, R., Shin, S.T., Guard, C.L., Erb, H.N. \& Frajblat, M., 2005. Prevalence of endometritis and its effects on reproductive performance of dairy cows. Theriogenology $64,1879-1888$. 
Gilbert, R. \& Schwark, W., 1992. Pharmacologic considerations in the management of peripartum conditions in the cow. Vet. Clin. N. Am-Food A. 8, 29.

Guilbault, L., Villeneuve, P. \& Dufour, J., 1988. Failure of exogenous prostaglandin F2 to enhance uterine involution in beef cows. Can. J. Anim. Sci. 68, 669-676.

Gustafsson, B., 1984. Therapeutic strategies involving antimicrobial treatment of the uterus in large animals. J. Am. Vet. Med. Assoc. 185, 1194-1198.

Gustafsson, B., Backstrom, G. \& Edqvist, L., 1976. Treatment of bovine pyometra with prostaglandin F2 [alpha]. An evaluation of a field study. Theriogenology $6,45-50$.

Hirsbrunner, G., Burkhardt, H.W. \& Steiner, A., 2006. Effects of a single administration of prostaglandin F2alpha, or a combination of prostaglandin F2alpha and prostaglandin E2, or placebo on fertility variables in dairy cows 3-5 weeks post partum, a randomized, double-blind clinical trial. Reprod. Biol. Endocrinol. 4, 65.

Hirvonen, J., Huszenicza, G., Kulcs, R.M. \& Pyörälä, S., 1999. Acute-phase response in dairy cows with acute postpartum metritis. Theriogenology 51, 1071-1083.

Huzzey, J.M., Duffield, T.F., LeBlanc, S.J., Veira, D.M., Weary, D.M. \& von Keyserlingk, M., 2009. Haptoglobin as an early indicator of metritis. J. Dairy. Sci. 92: 621-625.

Karstrup, C., Agerholm, J., Jensen, T., Swaro, L., Klitgaard, K., Rasmussen, E., Krogh, K. \& Pedersen, H., 2017. Presence and localization of bacteria in the bovine endometrium postpartum using fluorescence in situ hybridization. Theriogenology 92, 167-175.

Kasimanickam, R., Duffield, T., Foster, R., Gartley, C., Leslie, K., Walton, J. \& Johnson, W., 2004. Endometrial cytology and ultrasonography for the detection of subclinical endometritis in postpartum dairy cows. Theriogenology 62, 923.

Kasimanickam, R., Duffield, T., Foster, R., Gartley, C., Leslie, K., Walton, J. \& Johnson, W., 2005. The effect of a single administration of cephapirin or cloprostenol on the reproductive performance of dairy cows with subclinical endometritis. Theriogenology 63, 818-830.

Kennedy, P.C. \& Miller, R.B., 1993. Pathology of domestic animals. 4th edn. Academic Press, San Diego.

Kim, I.H. \& Kang, H.G., 2003. Risk factors for postpartum endometritis and the effect of endometritis on reproductive performance in dairy cows in Korea. J. Reprod. Dev. 49, 485-491.

Kindahl, H., Frederickson, G., Madej, A. \& Edqvist, L.E., 1984. Role of prostaglandins in uterine involution, Proceedings of the Xth Int. Cong. Anim Reprod and Al, Urbana-Champaign, 9-24.

Kiracofe, G., 1980. Uterine involution. Its role in regulating postpartum intervals. J. Anim. Sci. 51, 16-28.

LeBlanc, S., Duffield, T., Leslie, K., Bateman, K., Keefe, G., Walton, J. \& Johnson, W., 2002. Defining and diagnosing postpartum clinical endometritis and its impact on reproductive performance in dairy cows. J. Dairy. Sci. 85, 22232236.

Lech, M., Horstman, L. \& Callahan, C., 1988. Reproduction of dairy cattle. Postpartum disorders. AS-Cooperative Extension Service, Purdue University.

Lewis, G., 2004. Steroidal regulation of uterine immune defenses. Anim. Reprod. Sci. 82, 281-294.

Lindell, J. \& Kindahl, H., 1983. Exogenous prostaglandin F2 alpha promotes uterine involution in the cow. Acta Vet Scand. 24, 269-274.

Lindell, J., Kindahl, H., Jansson, L. \& Edqvist, L., 1982. Post-partum release of prostaglandin F2 [alpha] and uterine involution in the cow. Theriogenology 17, 237-245.

Masoumi, R., Towhidi, A., Javaremi, A. N., Nabizadeh, H. \& Zhandi, M., 2011. Influence of PGF2 alpha on semen quality and libido in Holstein bulls. Turk. J. Vet. Anim. Sci. 35, 1-6.

Masoumi, R., Badiei, A., Imam, G., Mosakhani, F. \& Curtis, A., 2012. Evaluation of uterotonic effects of Dinoprost in pyometric and clinically healthy lactating dairy cows. Reprod. Domest. Anim. 47, 477.

Masoumi, R., Badiei, A., Shahneh, A., Kohram, H., Dirandeh, E. \& Colazo, M. G., 2017. A Short Presynchronization with PGF2 $\alpha$ and GnRH Improves Ovarian Response and Fertility in Lactating Holstein Cows Subjected to a Heatsynch Protocol. Annals Anim. Sci. 17(1), 169-177.

Melendez, P., McHale, J., Bartolome, J., Archbald, L. \& Donovan, G., 2004. Uterine involution and fertility of holstein cows subsequent to early postpartum PGF2 [alpha] treatment for acute puerperal metritis. J. Dairy. Sci. 87, 32383246.

Mortimer, R., Ball, L., Olson, J., Huffman, E. \& Farln, P. 1984. The effect of PGF-2 alpha on reproductive performance of naturally bred dairy cows with or without pyometra. Theriogenology. 21, 869-874.

National Research Council. NRC. 2001. Nutrient requirements of dairy cattle. 2007;7:381.

Okano, A. \& Tomizuka, T., 1987. Ultrasonic observation of postpartum uterine involution in the cow. Theriogenology 27, 369-376.

Rivera, H., Lopez, H. \& Fricke, P., 2005. Use of intravaginal progesterone-releasing inserts in a synchronization protocol before timed Al and for synchronizing return to estrus in Holstein heifers. J. Dairy. Sci. 88, 957-968.

Roberts, S., 1971. Veterinary Obstetrics and Genital Diseases. Ithaca, New York. 464-465.

Sheldon, I., 2007. Endometritis in cattle. Pathogenesis, consequences for fertility, diagnosis and therapeutic recommendations. Reproduction Management Bulletin (Intervet) 2.

Sheldon, I. \& Dobson, H., 2000. Effect of administration of eCG to postpartum cows on folliculogenesis in the ovary ipsilateral to the previously gravid uterine horn and uterine involution. J. Reprod. Fertil. 119, 157-163.

Sheldon, I. \& Dobson, H., 2004. Postpartum uterine health in cattle. Anim. Reprod. Sci. 82, 295-306.

Sheldon, I., Noakes, D., Rycroft, A., Pfeiffer, D. \& Dobson, H., 2002. Influence of uterine bacterial contamination after parturition on ovarian dominant follicle selection and follicle growth and function in cattle. Reprod. 123, 837-845. 
Sheldon, I.M., Lewis, G.S., LeBlanc, S. \& Gilbert, R.O., 2006. Defining postpartum uterine disease in cattle. Theriogenology 65, 1516-1530.

Sheldon, I.M., Noakes, D.E., Rycroft, A.N. \& Dobson, H., 2003. The effect of intrauterine administration of estradiol on postpartum uterine involution in cattle. Theriogenology 59, 1357-1371.

Sheldon, I.M., Williams, E.J., Miller, A.N.A., Nash, D.M. \& Herath, S., 2008. Uterine diseases in cattle after parturition. Vet. J. 176, 115-121.

Steffan, J., Adrianang, S. \& Thibier, M., 1984. Treatment of metritis with antibiotics or prostaglandin F2 alpha and influence of ovarian cyclicity in dairy cows. Am. J. Vet. Res. 69, 1090-1094.

Vighio, G., Liptrap, R. \& Etherington, W., 1991. Oxytocin-prostagalandin interrelationships in the cow with pyometra. Theriogenology 35,, 1121-1129.

Wade, D. \& Lewis, G. 1996. Exogenous prostaglandin F2a stimulates utero-ovarian release of prostaglandin F2a in sheep. A possible component of the luteolytic mechanism of action of exogenous prostaglandin F2a. Domest. Anim. Endocrin. 13, 383-398.

Young, I., 1989. Responses to Dinoprost in the bovine early postpartum period. Vet. Rec., (UK). 124, 511-512.

Young, I. \& Anderson, D., 1986. First service conception rate in dairy cows treated with Dinoprost tromethamine early post partum. Vet. Rec. 118, 212-213.

Young, I., Anderson, D. \& Plenderleith, R. 1984. Increased conception rate in dairy cows after early post partum administration of prostaglandin F2 alpha THAM. Vet. Rec. 115: 429-431. 